\title{
Mouse Auxiliar Distribuidor de Carga de Trabalho na Interação com um Computador Pessoal para duas Mãos
}

\author{
Auxiliary Mouse Workload Distributor in Interaction with a Personal \\ Computer for Two Hands
}

\author{
Fabrício de Andrade Raymundo ${ }^{1}$ \\ Marcelo Borges de Andrade 1 \\ Marcus Vinícius Lopes Bezerra ${ }^{1}$ \\ Marina Couto Giordano de Oliveira ${ }^{1}$ \\ Sânya Léa Alves Rocha Lopes ${ }^{1}$ \\ Adriana Regina Martin ${ }^{1}$ \\ Paulo Gustavo Barboni Dantas Nascimento ${ }^{1}$ \\ ${ }^{1}$ Universidade de Brasília, Brasília, DF, Brasil
}

\begin{abstract}
Resumo
O presente artigo trata-se de uma análise da tecnologia protegida por pedido de patente de invenção de um dispositivo apontador, mais conhecido como mouse, que se propõe a permitir a distribuição da carga de trabalho na interação com um computador pessoal para as duas mãos. Objetivou-se verificar o estado da arte, o nível de maturidade tecnológica e o potencial mercadológico dessa invenção, a fim de analisar seu desenvolvimento, bem como suas rotas tecnológicas. Para tal, foi realizado um levantamento de dados nas bases internacionais Orbit - da Orbit Intelligence -, United States Patent and Trademark Office (USPTO), Espacenet - do European Patent Office (EPO) -, PATENTSCOPE - da World Intellectual Property Organization (WIPO) -, Web of Science - da Thomson Reuters Scientific - e na base nacional do Instituto Nacional de Propriedade Industrial (INPI).
\end{abstract}

Palavras-chave: Mouse. Apontador. Dispositivo.

\begin{abstract}
The present article is an analysis of the technology protected by patent application of a pointer device, better known as mouse, which proposes to allow the distribution of the workload in the interaction with a personal computer for the two hands, verifying in relation to the technology of the device the state of the art, the level of technological maturity and market potential. By searching the Orbit databases (ORBIT INTELLIGENCE, 2018), USPT (USPT, 2018) and Espacenet (ESPACENET, 2018), the research still accessed the international databases Patentscope and Web of Science (Web of Science, 2018), and the national database of the Instituto Nacional da Propriedade Industrial (INPI, 2018). The development of the technology was investigated, as well as the technological routes related to the technology under analysis.
\end{abstract}

Keywords: Mouse. Pointing. Device.

Áreas tecnológicas: Computação. Processamento Elétrico de Dados Digitais. 
Fabrício de Andrade Raymundo, Marcelo Borges de Andrade, Marcus Vinícius Lopes Bezerra, Marina Couto Giordano de Oliveira, Sânya Léa Alves Rocha Lopes, Adriana Regina Martin, Paulo Gustavo Barboni Dantas Nascimento

\section{Introdução}

Muitas atividades laborais exigem intensa interação com o computador. Grande parte dessa interação ocorre por meio do uso de periféricos (mouse e teclado), que realizam comandos de entrada de dados e exigem do homem a utilização de seus membros superiores.

Parte das doenças ocupacionais do trabalho está relacionada ao uso repetitivo das mãos e dos braços durante a operação desses periféricos, ocasionando o desgaste, a inflamação $e$ o enfraquecimento dos músculos e nervos demandados na execução dos movimentos (DOS SANTOS, 2017).

O dispositivo de apontamento para interface gráfica em computador pessoal, popularmente conhecido como mouse, é um dispositivo eletromecânico que visa à entrada de dados em computadores pessoais por meio de sensores de deslocamentos.

O primeiro registro desse tipo de dispositivo foi feito com Douglas Engelbart, em 1970, na Universidade de Standford (ENGELBART, 1970). Originalmente, a invenção recebeu a denominação de Indicador de Posição X-Y para Sistemas com Tela.

Em 1990, Reuben Nippoldt registrou a patente de um dispositivo de entrada de dados que consistia em uma esfera (trackball) que, ao ser manipulada, acionava sensores dispostos nos mecanismos rotatórios correspondentes às movimentações dos eixos $\mathrm{x} e \mathrm{y}$. Ao contrário do mouse de Engelbart, este dispositivo foi construído sobre uma base fixa (NIPPOLDT, 1990).

No pedido da patente USOO5999 169A, de 1999, Bobby C. Lee propôs um método em que um mecanismo de entrada de dois sinais digitais, por meio de dois dispositivos de entrada, multiplexados, com a finalidade de operar comandos em múltiplas direções, para cima e para baixo, para a esquerda e para a direita e movimentos de janelas, possibilitava a operação de múltiplos dispositivos computacionais de entrada de dados, ampliando o número de funcionalidades executadas simultaneamente (LEE, 1999).

O pedido de patente de invenção PI 0904503-1 analisado neste artigo traz uma proposta diferente da do mouse tradicional. Trata-se de um periférico computacional secundário, proposto por Rudi H. V. Els, da Fundação Universidade de Brasília (FUB), que permite auxiliar o operador a executar comandos externos ao teclado e ao mouse convencional nas ações de entrada de dados do usuário (ELS, 2009).

O dispositivo deve ser inserido no mercado como um complemento às interfaces tradicionais de computadores tradicionais com foco na prevenção das moléstias Lesão por Esforço Repetitivo (LER) e Doenças Osteoarticulares Relacionadas ao Trabalho (DORT). O público almejado são profissionais que trabalham por longo período em tarefas que exigem o uso contínuo do computador e de seus periféricos, especialmente do mouse (ELS, 2018).

O pedido de patente de invenção PI 0904503-1 foi depositado no Instituto Nacional de Propriedade Industrial (INPI) em 26 de agosto de 2009. Desde então, a FUB despendeu $\mathrm{R} \$ 1.342,00$ a título de anuidade e restauração. Na nova realidade imposta pela Emenda Constitucional n. 95, de 15 de dezembro de 2016, limitando os gastos públicos, uma nova era de eficiência e planejamento de gastos deve ser estabelecida (BRASIL, 2016). Nesse sentido, a qualificação do pedido de proteção industrial se justifica na perspectiva do gerenciamento dos ativos de propriedade industrial de um Núcleo de Inovação Tecnológica. 
Observa-se, nesse contexto, que a lentidão na análise de pedidos de patente gera um aumento de gasto para o depositante e a possibilidade de a tecnologia desenvolvida se tornar obsoleta ao final do processo. Isso levanta uma questão importante: o pedido de proteção da tecnologia desenvolvida por Rudi H. V. Els e depositado pela FUB ainda se justifica, considerando o histórico e o tempo decorrido de sua proposta? Para responder a essa pergunta, utilizou-se o método de prospecção tecnológica, por meio de mapeamento patentário, a fim de verificar a existência de tecnologias iguais ou similares, em quais países a tecnologia está sendo patenteada e quais seus potenciais mercados, buscando-se, assim, um estudo sobre a viabilidade econômica da tecnologia. Ou seja, a prospecção tecnológica possibilita conhecer todas as tecnologias existentes, identificar o estágio de maturidade da tecnologia em questão e saber como ela se insere na sociedade (QUINTELLA et al., 2011).

\section{Metodologia}

Este trabalho fundamentou-se na busca de documentos patentários, com foco em mouse auxiliar, nas bases de dados internacionais Orbit - da Orbit Intelligence -, United States Patent and Trademark Office (USPTO), Espacenet - do European Patent Office (EPO) -, PATENTESCOPE - da World Intellectual Property Organization (WIPO) -, Web of Science - da Thomson Reuters Scientific - e na base nacional do Instituto Nacional de Propriedade Industrial (INPI).

Foram realizadas duas estratégias de busca. Na primeira, para avaliar o desenvolvimento da tecnologia, utilizou-se as seguintes palavras-chaves nas bases de dados internacionais: "mouse", "computer", "mice", "therapeutic", "ergonomic", "orthopedic", "auxiliary", "repetitive strain injury" e "periph*", bem como seus respectivos termos em português na base de dados do INPI. Foram utilizados os campos de busca "título", "resumo" e o setor tecnológico computer technology. O limite temporal foi delimitado pelo campo "data de prioridade mais antiga" entre 01.01.2008 e 31.12.2017. Para ampliar e qualificar as buscas, optou-se por não limitar a abrangência territorial. A Tabela 1 apresenta a estratégia de busca em título e resumo associada a tecnologias similares. Utilizou-se o caractere de truncamento * (asterisco) e os operadores lógicos and e or.

Tabela 1 - Estratégia de busca em título e resumo associada a tecnologias similares

\begin{tabular}{|c|c|}
\hline EXPRESSÃO DE BUSCA & RESUltados \\
\hline ((mouse) and (computer)) & 6.344 \\
\hline (mouse or mice) and (computer) & 6.364 \\
\hline (mouse or mice or periph*) and (computer) & 10.566 \\
\hline (mouse or mice or periph*) and (computer) and (therapeutic) & 5 \\
\hline (mouse or mice or periph*) and (computer) and (therapeutic or ergonomic) & 59 \\
\hline (mouse or mice or periph*) and (computer) and (therapeutic or ergonomic or orthopedic) & 59 \\
\hline $\begin{array}{c}\text { (mouse or mice or periph }{ }^{*} \text { ) and (computer) and (therapeutic } \\
\text { or ergonomic or orthopedic or auxiliary) }\end{array}$ & 242 \\
\hline $\begin{array}{l}\text { (mouse or mice or periph*) and (computer) and (therapeutic or } \\
\text { ergonomic or orthopedic or auxiliary or repetitive strain injury) }\end{array}$ & 243 \\
\hline
\end{tabular}

Fonte: Elaborada pelos autores deste artigo (2018) 
A segunda estratégia de busca foi realizada com foco na avaliação das rotas tecnológicas. Para a recuperação de informações nos bancos de dados, foram utilizadas as seguintes palavras-chaves: "mouse", "computer", "touch panel", "haptic", "gaze detection", "voice controller", "hand tracking", "controller", "hand gesture", "human interaction", "natural interface" e "brain computer interface" e seus respectivos termos em português na base de dados do INPI. Foram utilizados os campos de busca "título", "resumo" e o setor tecnológico computer technology. O limite temporal foi delimitado pelo campo "data de prioridade mais antiga" entre 01.01.2008 e 31.12.2017 e não foi adotada alguma limitação no que se refere à abrangência territorial, com vistas a ampliar as buscas. Além disso, utilizou-se o caractere de truncamento "?" (interrogação) e os operadores lógicos and e or. A Tabela 2 apresenta a estratégia de busca em título e resumo associada a rotas tecnológicas.

Tabela 2 - Estratégia de busca em título e resumo associada a rotas tecnológicas

$\begin{array}{cc}\text { EXPRESSÃO DE BUSCA } & \text { RESULTADOS } \\ \text { (computer) and (touch panel?) } & 983 \\ \text { (computer) and (touch panel? or haptic?) } & 1.195 \\ \text { (computer) and (touch panel? or haptic? or gaze detection) } & 1.215 \\ \text { (computer) and (touch panel? or haptic? or gaze detection or voice controller) } & 1.220 \\ \text { (computer) and (touch panel? or haptic? or gaze detection } & 1.227 \\ \text { (computer) and (touch panel? or haptic? or gaze detection or voice } \\ \text { controller or hand tracking or controller? or hand gesture?) } \\ \text { (computer) and (touch panel? or haptic? or gaze detection or voice controller } \\ \text { or hand tracking or controller? or hand gesture? or human interaction) } \\ \text { (computer) and (touch panel? or haptic? or gaze detection or voice controller or hand } \\ \text { tracking or controller? or hand gesture? or human interaction or natural interface) } \\ \text { (computer) and (touch panel? or haptic? or gaze detection or voice } \\ \text { controller or hand tracking or controller? or hand gesture? or human } \\ \text { interaction or natural interface or brain computer interface) }\end{array}$

Fonte: Elaborada pelos autores deste artigo (2018)

Além das estratégias de busca, este estudo contou com a técnica de entrevista presencial com o inventor da patente, por meio da qual foi possível coletar informações estratégicas como expectativa de lançamento do produto no mercado, tecnologias concorrentes, entre outras.

O software Microsoft Office Exce ${ }^{\circledR}$ foi utilizado para a análise e a elaboração dos gráficos constantes neste artigo.

\section{Resultados e Discussão}

A Figura 1 demonstra os principais códigos da International Patent Classification (IPC) em que a tecnologia está depositada. O código mais representativo é o IPC G06F-003/0354. Essa classe abrange dispositivo com detecção de movimentos relativos em $2 \mathrm{D}$ entre o dispositivo ou sua parte operativa e um plano ou superfície (WORLD INTELLECTUAL PROPERTY ORGANIZATION, 2018). 
Destaca-se a relevância dos códigos G06F-003/039 e G06F-003/033. A classe G06F-003/039 abrange acessórios; a classe G06F-003/033, dispositivos de indicação deslocados ou posicionados pelo usuário e acessórios (WORLD INTELLECTUAL PROPERTY ORGANIZATION, 2018).

Figura 1 - Códigos de IPC mais frequentes

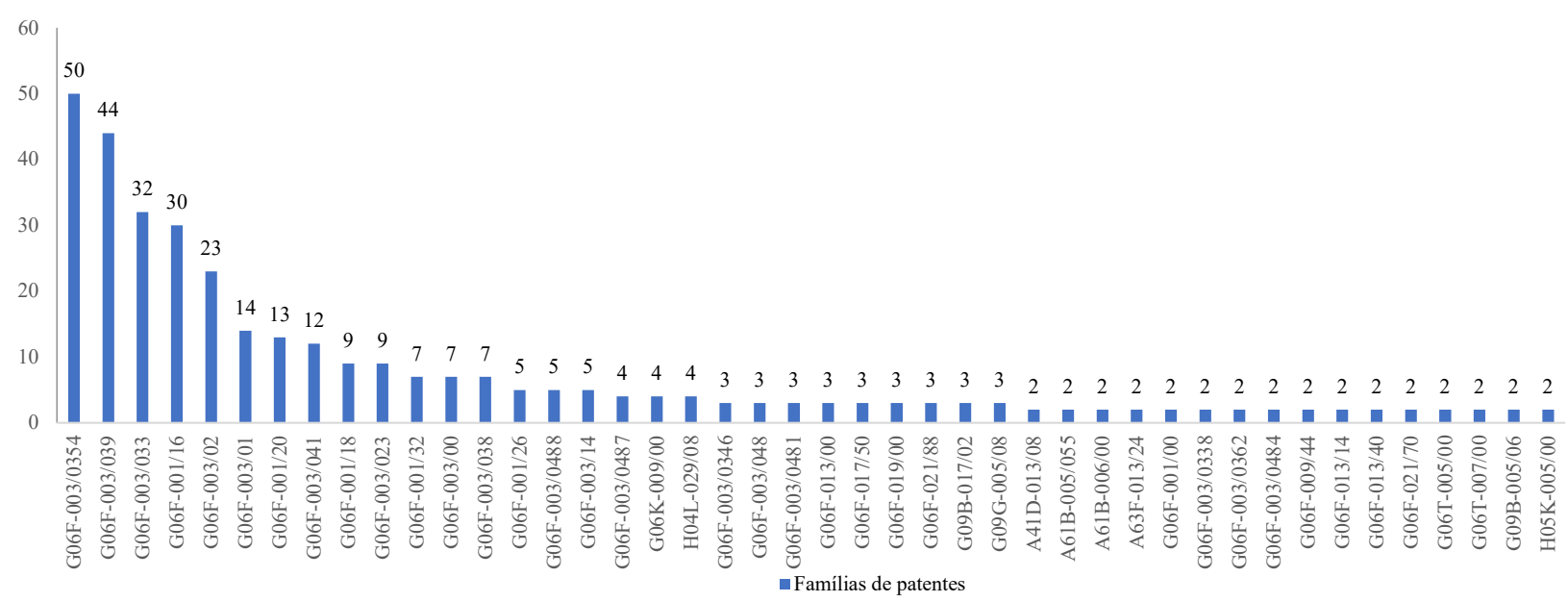

Fonte: Elaborada pelos autores deste artigo (2018)

Na Figura 2, uma análise sobre o domínio da tecnologia ao redor do mundo apresenta as patentes depositadas por país de prioridade, mostrando o grau de domínio da tecnologia, $e$ qual país é o detentor de maior relevância na área tecnológica dessa invenção.

Observa-se que a China é o país que mais detém depósitos da tecnologia pesquisada, com 73,09\% dos documentos patentários, seguida pelos Estados Unidos da América (EUA), com $6,43 \%$, e pela Coreia do Sul, com 5,22\%. O Brasil, segundo os dados obtidos, não tem uma participação relevante nos depósitos dessa tecnologia.

Figura 2 - Principais países de prioridade

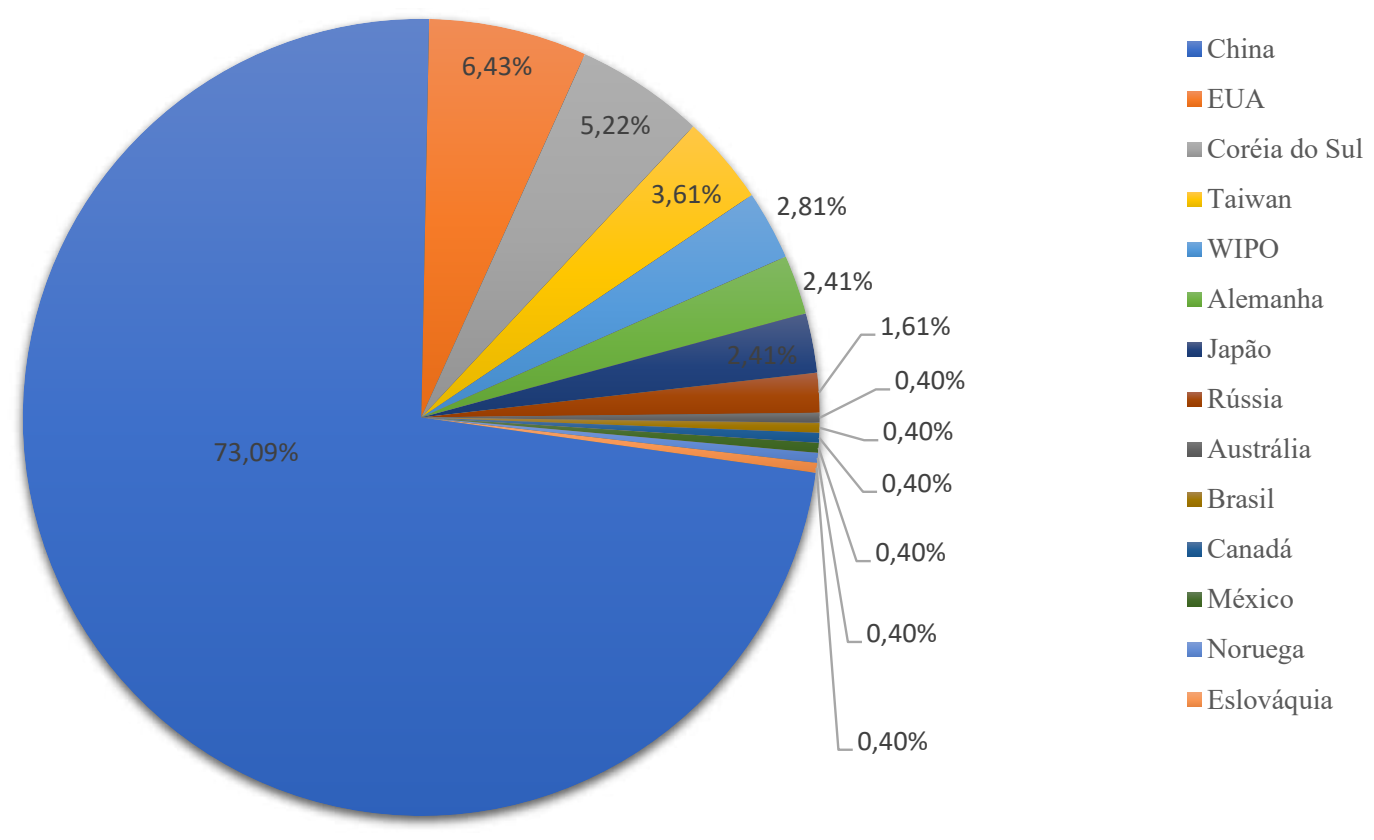

Fonte: Elaborada pelos autores deste artigo (2018) 
Na Figura 3, verifica-se que os depositantes das patentes estão distribuídos entre universidades, institutos e empresas, ficando evidente a liderança das organizações chinesas no mercado de depósitos desse segmento. Esse dado está em consonância com o da Figura 2, que apresenta a China como maior detentora dos documentos patentários.

As cinco universidades, instituições e empresas que mais depositaram patentes são a Chengdu Shengshi Puyi Technology, a Harbin Normal University, a Hon Hai Precision Industry, a China University of Mining \& Technology e a Jiangsu Huangming Energy Technology.

Observa-se que universidades e empresas realizaram o depósito de patentes, o que demonstra uma visão mercadológica por parte das universidades.

Figura 3 - Principais depositantes

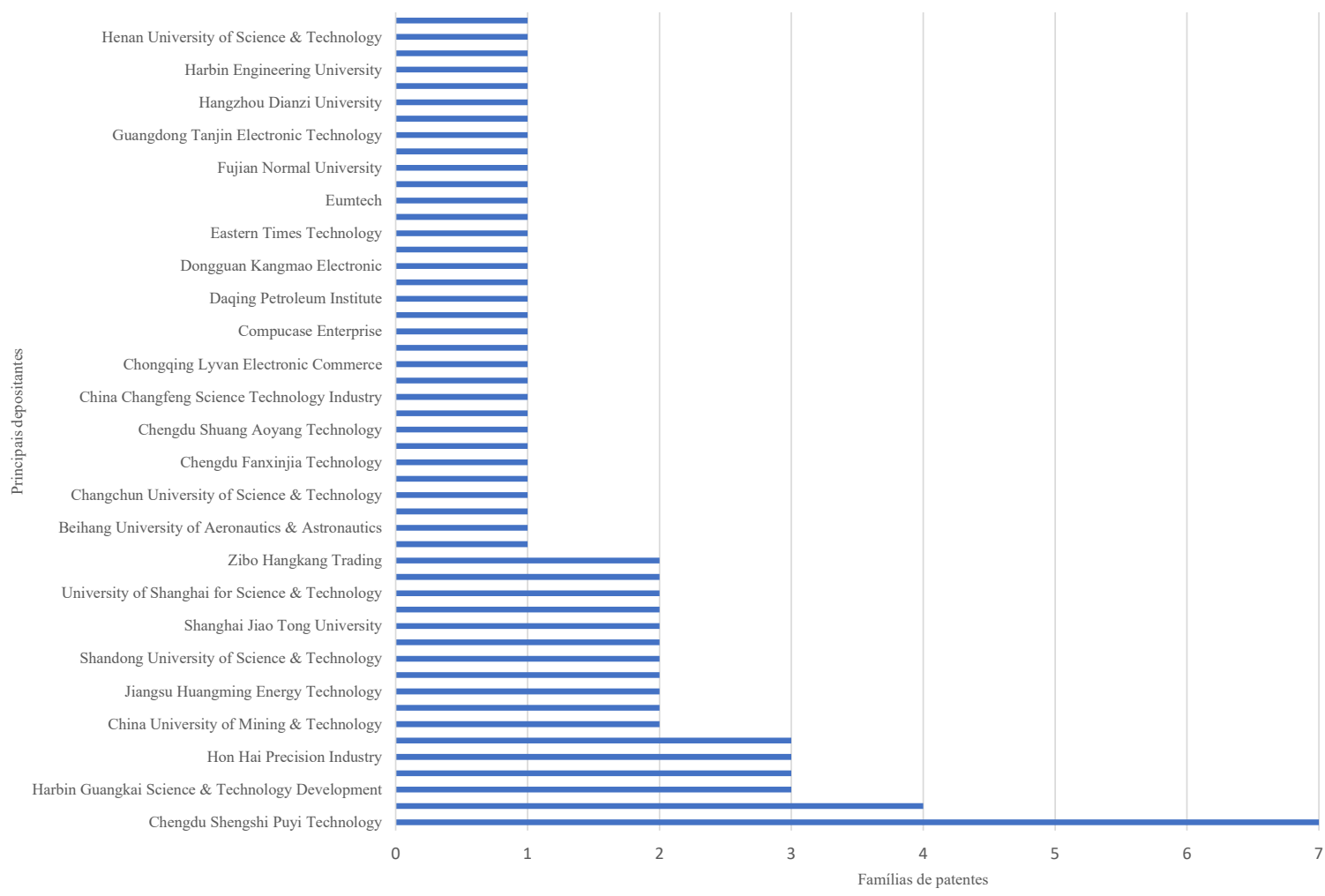

Fonte: Elaborada pelos autores deste artigo (2018)

No limite temporal delimitado, de 2008 a 2012, conforme ilustra a Figura 4, houve um acréscimo nos depósitos de documentos patentários realizados pelas organizações chinesas e, de 2013 a 2017, houve um pequeno decréscimo nos depósitos de documentos patentários efetuados pelas organizações chinesas. Ainda, nota-se que, em 2010, cresceu o número de patentes depositadas pela Alemanha. 
Figura 4 - Dispersão anual dos depósitos de pedidos de patente

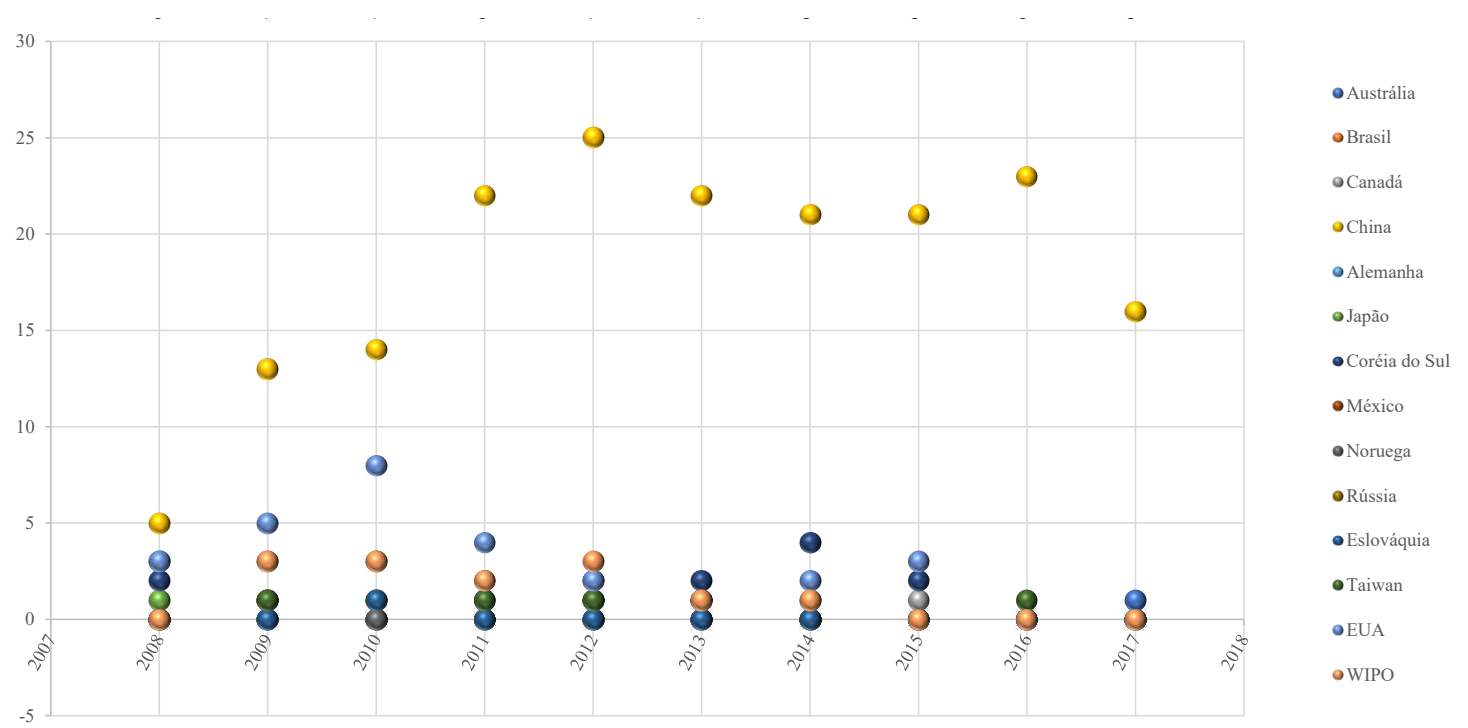

Fonte: Elaborada pelos autores deste artigo (2018)

No que se refere ao status legal dos documentos patentários, percebe-se que o maior percentual corresponde ao de patentes concedidas (29,63\%), seguido pelas expiradas $(26,34 \%)$, caducadas $(24,28 \%)$, pendentes $(17,70 \%)$ e revogadas $(2,06 \%)$.

Figura 5 - Status legal dos documentos patentários

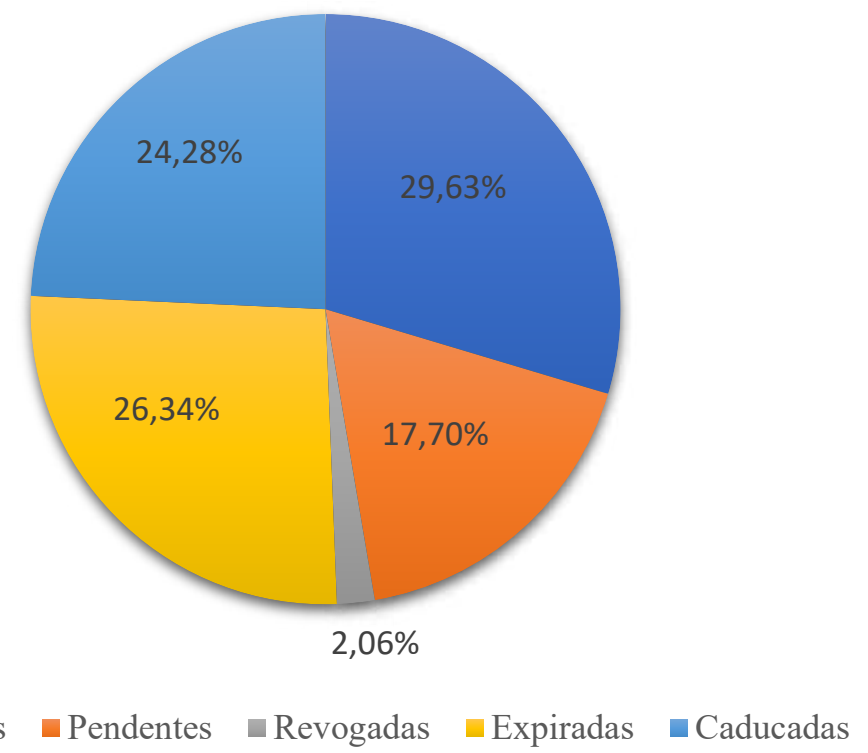

Fonte: Elaborada pelos autores deste artigo (2018)

\subsection{Análise da Maturidade Tecnológica}

O Nível de Maturidade Tecnológica (NMT) é uma sistemática métrica utilizada para obter o grau de maturidade de uma determinada tecnologia (NATIONAL AERONAUTICS AND SPACE ADMINISTRATION, 2012). Em inglês, o NMT é denominado Technology Readiness Level (TRL). Essa sistemática métrica foi desenvolvida pelo pesquisador da National Aeronautics and Space 
Administration (NASA) [Administração Nacional de Aeronáutica e Espaço] Stan Sadin em 1974. A primeira escala foi concebida com sete níveis. Nos anos 1990, a escala passou a contar com nove níveis, que variam de TRL 1 a TRL 9 (BANKE, 2010) e permitem avaliar, em um determinado instante, o nível de maturidade de uma tecnologia em particular e, em uma comparação consistente de maturidade entre diferentes tipos de tecnologia, todo o contexto de um sistema específico, sua aplicação e seu ambiente operacional (MANKINS, 1995)

Uma nova tecnologia não nasce pronta. Para que esteja preparada para uso e comercialização, deve estar sujeita a experimentação, a simulação, a refinamento, a prototipagem $e$ a ensaios de desempenho (VELHO et al., 2017). Até lá, passará pelos níveis TRL 1 a TRL 9. O NMT é uma ferramenta bastante importante para elucidar quão madura está uma tecnologia em particular (BANKE, 2010), pois permite a elaboração de um planejamento adequado, reduzindo riscos inerentes ao processo de desenvolvimento tecnológico, de modo que fique dentro do prazo e orçamento esperados (MORESI et al., 2017).

Em linhas gerais, os TRLs 1 a 3 referem-se à pesquisa básica e parcialmente aplicada, denominada de bancada. Os TRLs 4 a 6 referem-se ao desenvolvimento tecnológico focado em pesquisa aplicada, denominado de piloto, e os TRLs 7 a 9 referem-se à finalização das tecnologias, denominada de demonstração e, depois, de comercial (QUINTELLA, 2017).

O mouse auxiliar, objeto de análise deste artigo, encontra-se no nível 4 de maturidade tecnológica (validação de componentes e/ou sistemas em ambiente laboratorial). Conforme Figuras 6 e 7, um protótipo do mouse já foi desenvolvido e validado somente em laboratório (ELS, 2018).

Figura 6 - Mouse auxiliar

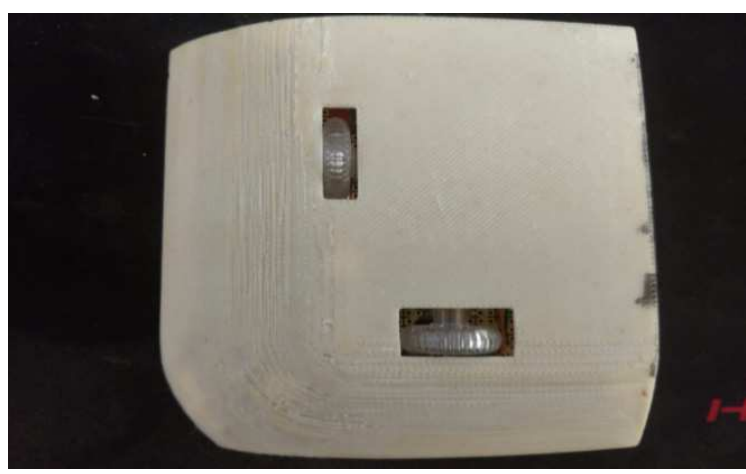

Fonte: Acervo do inventor (2018)
Figura 7 - Mouse auxiliar

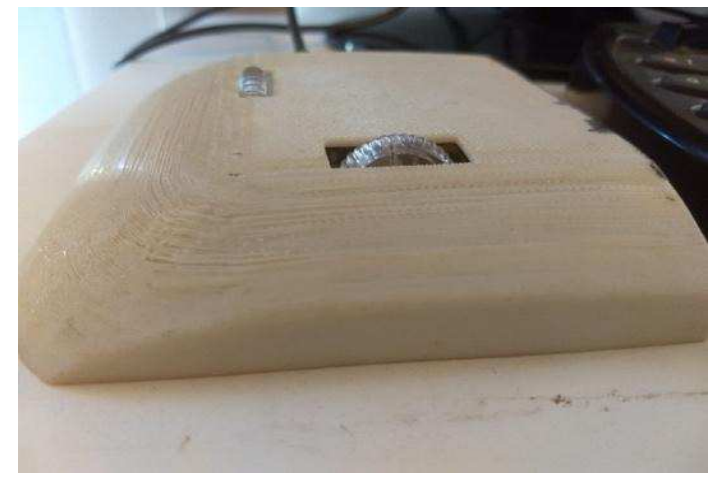

Fonte: Acervo do inventor (2018)

\subsection{Análise SWOT}

A partir do levantamento de dados, foi possível elaborar uma matriz de indicadores organizada em quatro setores - oportunidades, ameaças, fraquezas e forças - atinentes ao pedido de patente PI0904503-1 A2, conforme apresenta o Quadro 1. Os achados da análise SWOT demonstram, de forma lógica, que a tecnologia pesquisada encontra-se em desequilíbrio - desvantagem - se for tomada como referência a relação "Forças x Ameaças". Por outra via, a relação "Oportunidades x Fraquezas" apresenta-se equilibrada, ainda que também em desvantagem se for considerado que o quesito "Oportunidades" depende de variáveis externas aos atores envolvidos no desenvolvimento da tecnologia. 
Quadro 1 - Análise SWOT sobre a tecnologia do pedido de patente PI0904503-1 A2

\begin{tabular}{|c|c|}
\hline Fabricação em larga escala visando á redução de custos. & AmEAçAS \\
\hline Aumento das doenças do trabalho LER/DORT. & $\begin{array}{c}\text { Evolução tecnológica e/ou rotas tecnológicas } \\
\text { alternativas (tecnologia/produto substituído). }\end{array}$ \\
\hline Investimento/financiamento externo. & Entrada de fortes concorrentes. \\
\hline Parcerias estratégicas. & \\
\hline Novas formas de marketing mais eficientes e baratas. & \\
\hline Fraquezas & Forças \\
\hline Design pouco ergonômico. & Tecnologia. \\
\hline Facilidade de entrada de concorrentes. & \\
\hline Mudança de hábito. & \\
\hline Preço estimado pouco competitivo. & \\
\hline Recursos limitados. & \\
\hline Força de vendas limitada. & \\
\hline
\end{tabular}

Fonte: Elaborado pelos autores deste artigo (2018)

A Figura 8, a seguir, demonstra os principais códigos de IPC das tecnologias similares à invenção analisada. O código mais representativo é o IPC G06F-003. Essa classe abrange disposições de entrada, para transferir dados a serem processados por uma forma capaz de ser manipulada pelo computador; e disposições de saída, para transferir dados da unidade de processamento por uma unidade de saída (WORLD INTELLECTUAL PROPERTY ORGANIZATION, 2018).

Figura 8 - Códigos de IPC mais frequentes

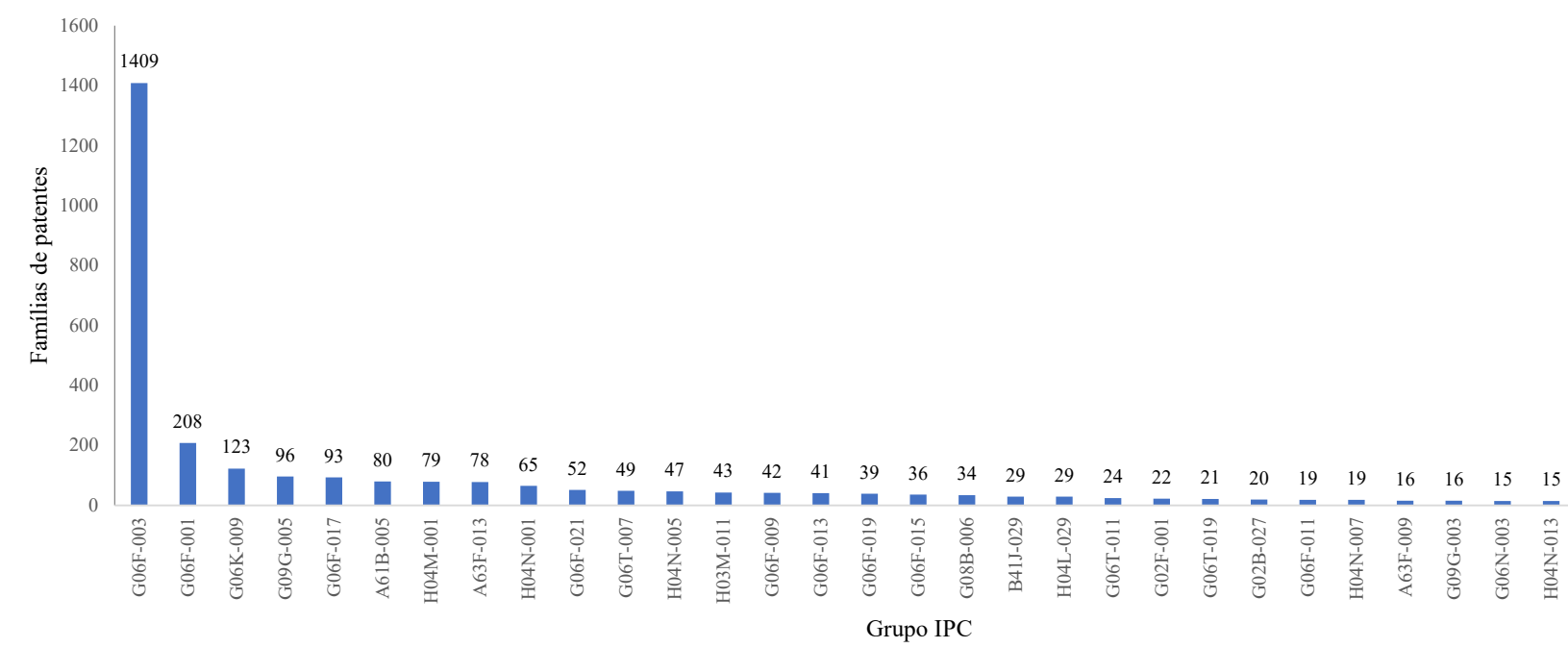

Fonte: Elaborada pelos autores deste artigo (2018) 


\subsection{Análise das Rotas Tecnológicas}

Como resultado da análise sobre o domínio da tecnologia ao redor do mundo, a Figura 9 apresenta os documentos patentários depositados com tecnologia similar por país de prioridade, sendo possível analisar qual país é o detentor de maior relevância na área tecnológica.

Observa-se que os três países que mais detêm tecnologias similares à tecnologia analisada são China, com 30,97\%; seguida pelo Japão, com 26,55\%; e pelos EUA, com 15,83\%.

Figura 9 - Principais países de prioridade

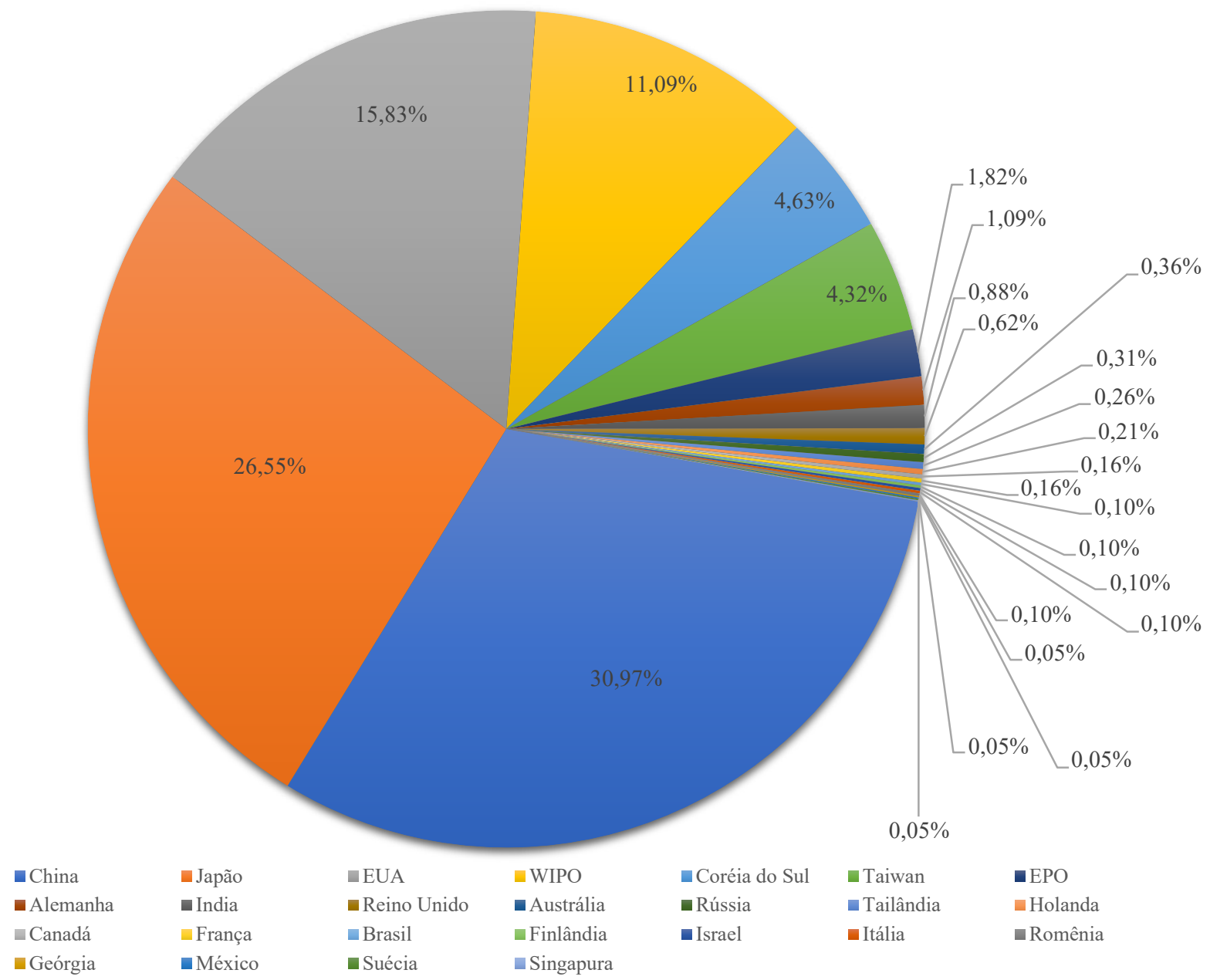

Fonte: Elaborada pelos autores deste artigo (2018)

Nota-se, na Figura 10, que as universidades, instituições e empresas que mais depositaram patentes com tecnologias relacionadas à invenção analisada são: Sharp, Canon, Konica Minolta, Fujitsu, Brother Kogyo, Xián Jiaotong University, Colopl, IBM, Casio Computer, Samsung Eletronics, Toshiba, Kyocera, Microsoft Technology Licensing, Beijing University of Technology e Konami Digital Entertainment.

Assim, no que se refere ao depósito de patente de tecnologia similar à invenção analisada, as universidades, instituições e empresas chinesas deixam de ser protagonistas e passam a dividir a liderança com empresas japonesas. 
Figura 10 - Principais depositantes

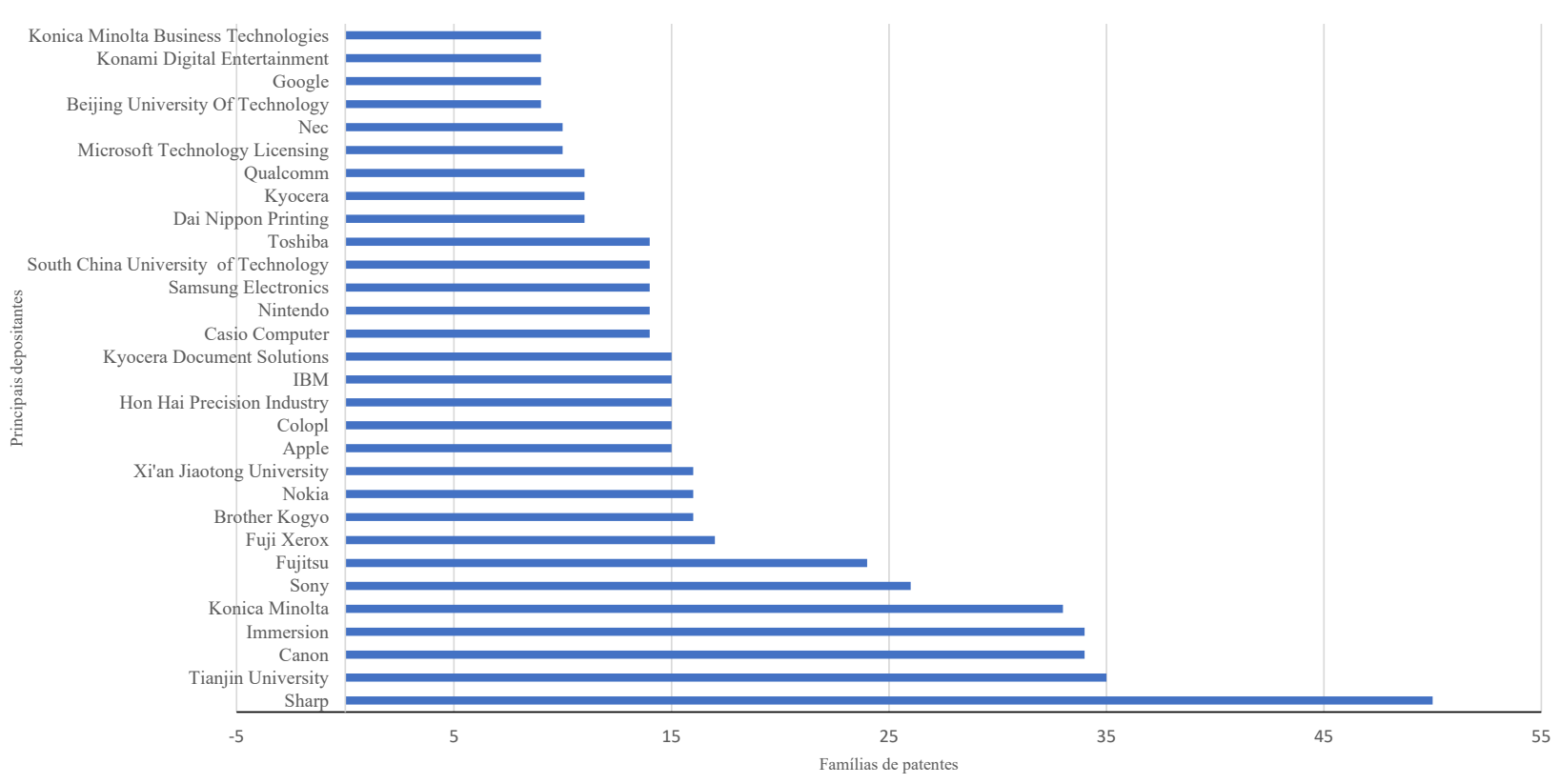

Fonte: Elaborada pelos autores deste artigo (2018)

A Figura 11 demonstra a dispersão cronológica dos depósitos de pedidos de patentes, indicando que há um crescimento linear de documentos patentários ao longo dos anos. Demonstra também uma superação da China em relação ao Japão a partir de 2015, mas ainda inferior aos EUA. Contudo, a partir de 2016, o Japão e os EUA decaem nos depósitos de patentes e a China não apenas continua crescendo, mas também os supera.

Figura 11 - Dispersão anual dos depósitos de pedidos de patente

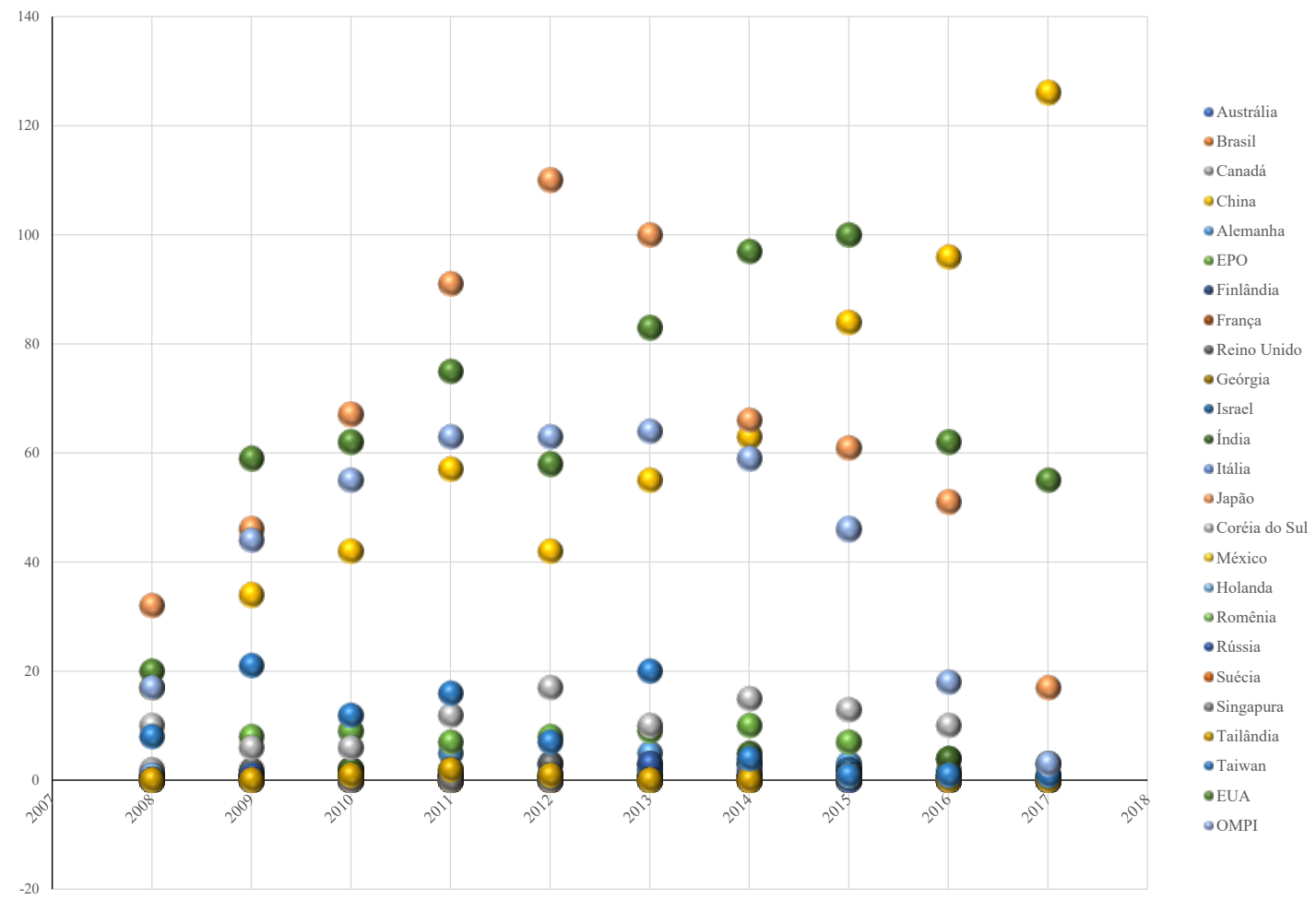

Fonte: Elaborada pelos autores deste artigo (2018) 
No que se refere ao status legal dos documentos patentários, percebe-se que o maior percentual corresponde ao de patentes concedidas (49,39\%), seguido pelas pendentes $(29,38 \%)$, caducadas $(13,50 \%)$, revogadas $(4,81 \%)$ e expiradas $(2,98 \%)$.

Figura 12 - Status legal dos documentos patentários

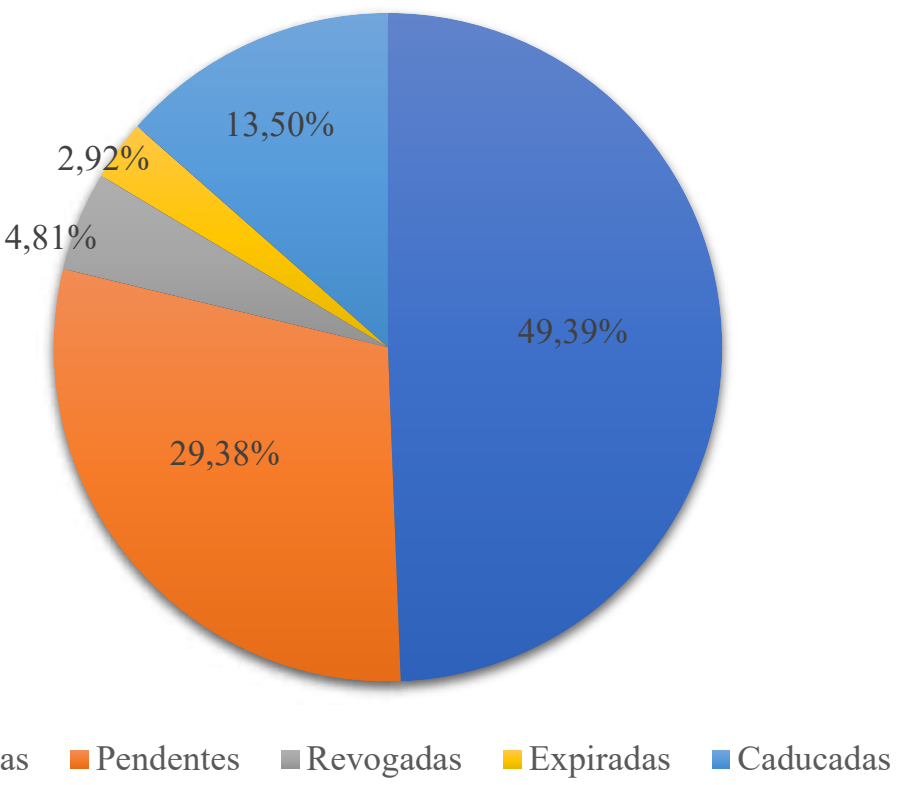

Fonte: Elaborada pelos autores deste artigo (2018)

Também foi realizada uma busca da produção de artigos científicos, com o objetivo de demonstrar o nível de publicações relacionadas à tecnologia do pedido de patente, de acordo com os temas ciência da computação e tecnologias.

Diante da coleta de dados dos artigos publicados sobre mouse de computador e áreas tecnológicas relacionadas, verifica-se, na Figura 13, a evolução anual dessas publicações, de 2008 a 2017, com destaque para uma queda dos registros no ano de 2013.

Figura 13 - Evolução anual de artigos publicados sobre mouse auxiliar, de 2008 a 2017

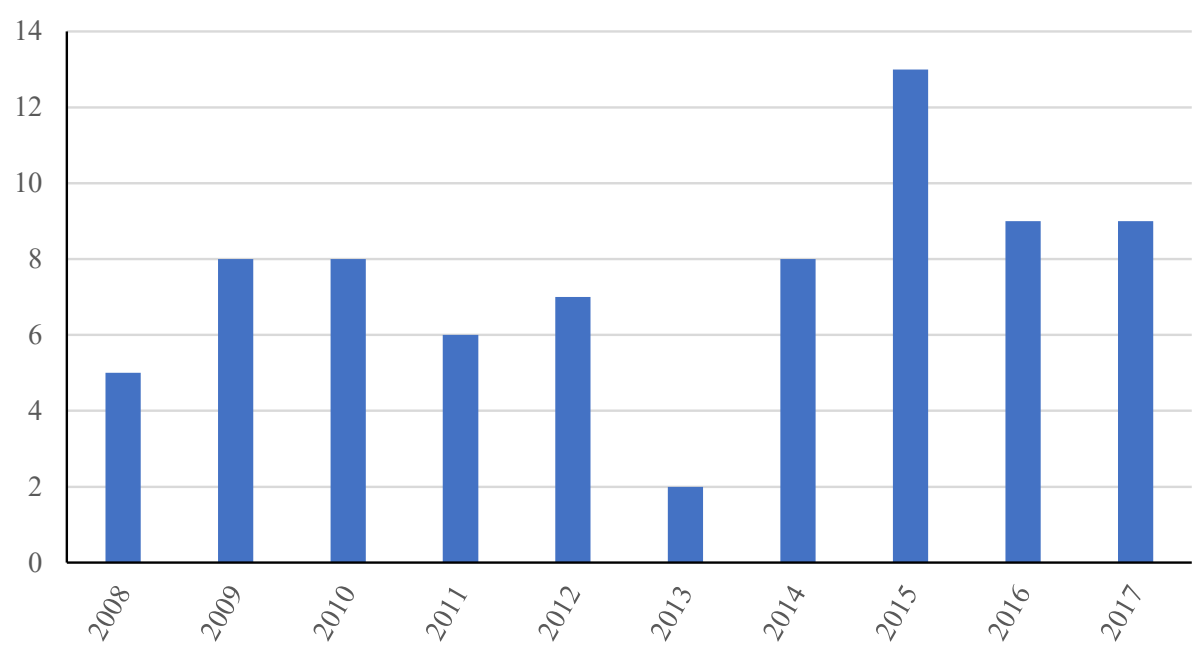

Fonte: Elaborada pelos autores deste artigo (2018) 
Em que pese a China ser a maior detentora dos documentos patentários de tecnologias similares à invenção analisada, os EUA são protagonistas na publicação de artigos sobre mouse de computador (Figura 14).

Figura 14 - Distribuição de artigos publicados por país

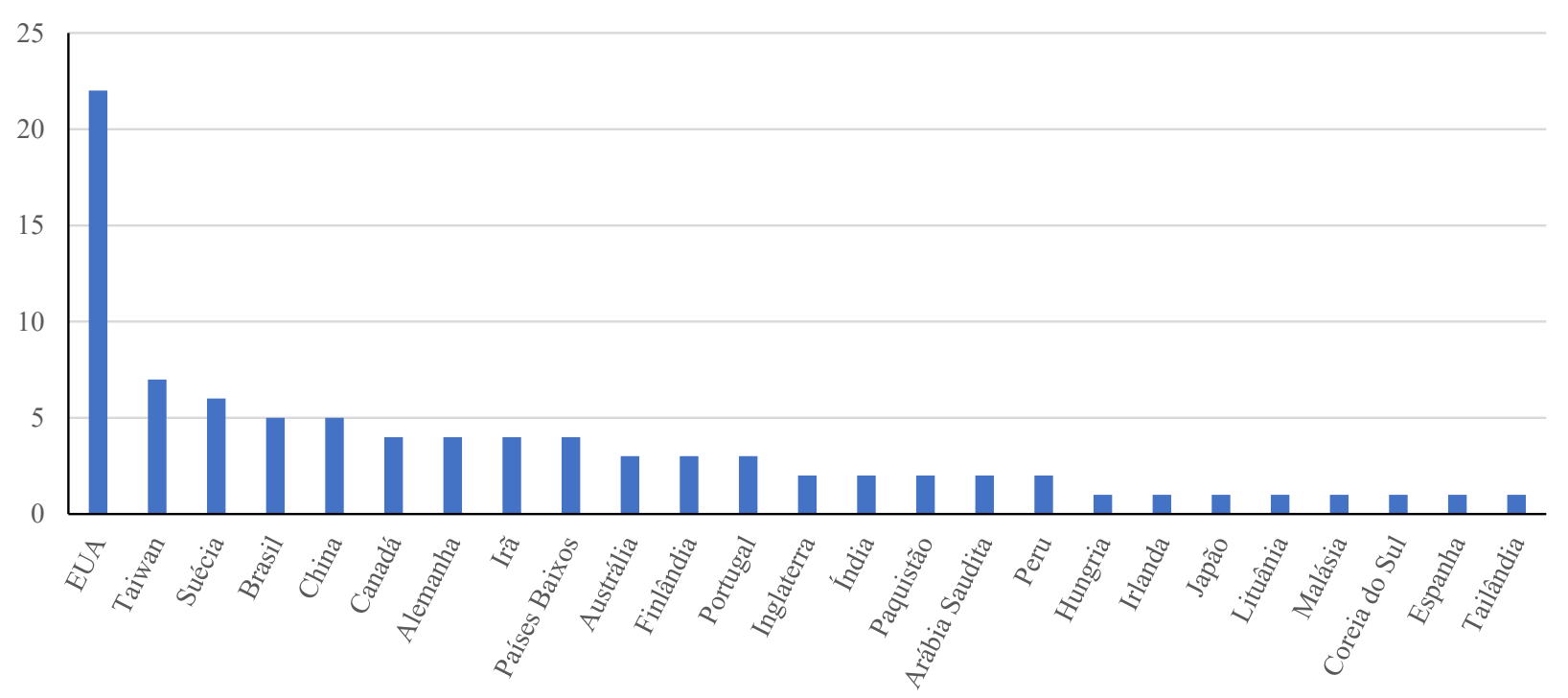

Fonte: Elaborada pelos autores deste artigo (2018)

Em uma análise do grau de domínio da tecnologia (patentes depositadas) em razão do conhecimento científico (artigos publicados) por país a respeito do mouse de computador, verifica-se o domínio da tecnologia pela China e o domínio do conhecimento científico pelos EUA.

Figura 15 - Dispersão da produção de artigos e patentes por país

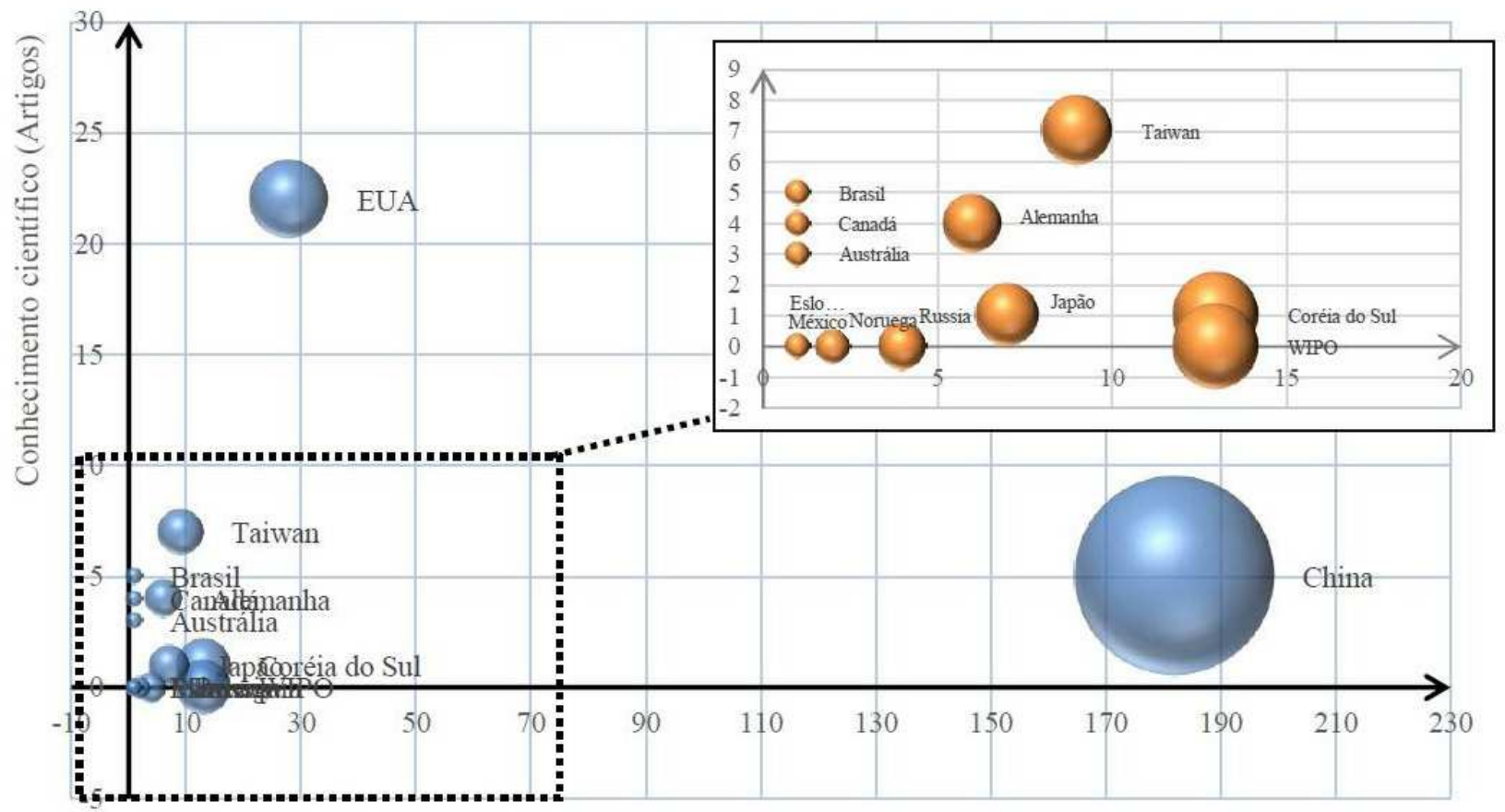

Domínio da tecnologia (Patentes)

Fonte: Elaborada pelos autores deste artigo (2018) 


\section{Considerações Finais}

Depois de estudar a patente e escolher os indicadores a serem utilizados nas bases de dados internacionais e nacional, foram obtidas as informações necessárias para as análises.

Identificou-se o setor empresarial como líder de depósito das patentes dessa linha tecnológica, uma vez que o setor acadêmico possui um baixo percentual de títulos e não foi encontrado algum depósito de pessoa física.

Apesar de a China deter 73,09\% dos documentos patentários, nota-se que as universidades, instituições e empresas chinesas deixam de ser protagonistas e passam a dividir a liderança com empresas japonesas.

Constatou-se, ainda, que a tecnologia em estudo caracteriza-se por um nível de maturidade tecnológica inicial, enquadrado no TRL 4.

Entende-se, pelo exposto neste artigo, que a patente em questão propõe-se a minimizar, de forma eficiente, os problemas com saúde relacionados a LER e a DOR, na medida em que distribui a carga de trabalho na interação do usuário com o computador por meio de um dispositivo auxiliar, sendo importante sua introdução no mercado quanto antes. Nesse sentido, apesar de existir uma evolução tecnológica do pedido patentário como touch panel, haptic e voice controller, o inventor acredita que o produto tenha um ciclo de vida potencial para os próximos 10 anos.

Dito isso, recomenda-se que o inventor e a FUB desenvolvam ações que envolvam potenciais parcerias, editais de subvenção ou licenciamento, para elevar a maturidade tecnológica do mouse auxiliar e agilizar sua introdução no mercado, evitando-se, assim, que a patente se torne obsoleta.

\section{Referências}

BANKE, J. Technology readiness levels demystified. 2010. Disponível em: < https://www.nasa. gov/topics/aeronautics/features/trl_demystified.html>. Acesso em: 29 dez. 2018.

BRASIL. Emenda Constitucional n. 95, de 15 de dezembro de 2016. [2016]. Altera o Ato das Disposições Constitucionais Transitórias, para instituir o Novo Regime Fiscal, e dá outras providências. Disponível em: <http://www.planalto.gov.br/ccivil_03/constituicao/emendas/emc/ emc95.htm>. Acesso em: 19 jun. 2018.

DOS SANTOS, F. R. et al. Ergonomia de escritório: fatores corretivos relacionados à prevenção de LER/DORT. Revista Científica Faculdades do Saber, Mogi Guaçu, v. 2, n. 3, p. 156-167, 2017.

\section{ELS, Rudi H. Van. Entrevista concedida a Marina Couto Giordano de Oliveira e a Marcelo} Borges de Andrade. Brasília, DF, 15 maio 2018.

Mouse auxiliar para permitir a distribuição da carga de trabalho na interação com um computador pessoal para as duas mãos. BR Pat. PI0904503-1 A2, 26 ago. 2009. 16 p.

ENGELBART, D. C. X-Y position indicator for a display system. US Pat. 3541541A, 17 nov. 1970. 7 p. 
EUROPEAN PATENT OFFICE (EPO). Espacenet: base de dados on-line. [2018]. Disponível em: $<$ https://worldwide.espacenet.com/>. Acesso em: 30 maio 2018.

INSTITUTO NACIONAL DA PROPRIEDADE INDUSTRIAL (INPI). Base de dados on-line. [2018]. Disponível em: <http://www.inpi.gov.br/>. Acesso em: 30 maio 2018.

\section{LEE, B. C. Computer graphical user interface method and system for supporting multiple} two-dimensional movement inputs. US Pat.4952919. 7 dez. 1999. 12 p.

MANKINS, J. C. Technology readiness levels. A white paper. 1995. Disponível em: <http://www. artemisinnovation.com/images/TRL_White_Paper_2004-Edited.pdf >. Acesso em: 29 dez. 2018.

MORESI, E. et al. Análise de níveis de prontidão: uma proposta para empresas nascentes. In: CONGRESO IBERO-AMERICANO EM INVESTIGACIÓN CUALITATIVA, 6., Salamanca, 2017. Atas... Salamanca: Ciaiq, 2017. 4 v. Disponível em: <https://proceedings.ciaiq.org/index.php/ ciaiq2017/article/view/1127>. Acesso em: 29 dez. 2018.

\section{NATIONAL AERONAUTICS AND SPACE ADMINISTRATION (NASA). Technology readiness}

levels: introduction. 2012. Disponível em: < https:/www.nasa.gov/directorates/heo/scan/engineering/ technology/txt_accordion1.html>. Acesso em: 30 maio 2018.

NIPPOLDT, R. E. Trackball mechanism. US Pat.4952919, 28 ago. 1990. 8 p.

ORBIT INTELLIGENCE. Base de dados on-line. [2018]. Disponível em: <https://www.orbit.com>. Acesso em: 30 mai. 2018.

QUINTELLA, C. M. A Revista Cadernos de Prospecção e os Níveis de Maturidade de Tecnologias (TRL). Cadernos de Prospecção, Salvador, v. 10, n. 1-2, p.1, jan./mar. 2017.

QUINTELLA, C. M. et al. Prospecção tecnológica como uma ferramenta aplicada em ciência e tecnologia para se chegar à inovação. Revista Virtual de Química, Salvador, v. 3, n. 5, p. 406415, nov. 2011.

UNITED STATES PATENT AND TRADEMARK OFFICE (USPTO). Base de dados on-line. [2018]. Disponível em: <https://www.uspto.gov/patents-application-process/search-patents/>. Acesso em: 30 mai. 2018.

VELHO, S. R. K. et al. Nível de Maturidade Tecnológica: uma sistemática para ordenar tecnologias.

Parcerias Estratégicas, Brasília, DF, v. 22, n. 45, p. 119-140, jul./dez. 2017.

THOMSON REUTERS SCIENTIFIC. Web of Science: base de dados on-line. [2018]. Disponível em: <https://https://www.periodicos.capes.gov.br />. Acesso em: 30 maio 2018.

WORLD INTELLECTUAL PROPERTY ORGANIZATION (WIPO). PATENTSCOPE: base de dados on-line. [2018]. Disponível em: < https://patentscope.wipo.int/> Acesso em: 30 maio 2018. 


\section{Sobre os Autores}

\section{Fabrício de Andrade Raymundo}

E-mail: fbi130620@gmail.com

Formação: Mestrando em Propriedade Intelectual e Transferência de Tecnologia para Inovação, pelo Programa de Pós-Graduação em Propriedade Intelectual e Transferência de Tecnologia para a Inovação da Universidade de Brasília (PROFNIT/UnB); pós-graduado em Literatura, pela UnB, em Ciências Policiais, pelo Instituto Superior de Ciências Policiais (ISCP), e em Ciências Jurídicas, pela Universidade Cruzeiro do Sul (UNICSUL); bacharel em Direito, pela Universidade da Cidade de São Paulo, graduado em Letras e Literatura Espanhola, pela UnB, e em Segurança Pública, pelo ISCP.

Endereço profissional: SSP/DF. SDN A, Asa Norte - Brasília, DF. CEP: 70620-000.

\section{Marcelo Borges de Andrade}

E-mail: marcelo.and@gmail.com

Formação: Mestrando em Propriedade Intelectual e Transferência de Tecnologia para Inovação, pelo Programa de Pós-Graduação em Propriedade Intelectual e Transferência de Tecnologia para a Inovação da Universidade de Brasília (PROFNIT/UnB); especialista em Engenharia de Sistemas, pela ESAB Brasil; e graduado em Engenharia de Computação, pelo Instituto de Educação Superior de Brasília IESB.

Endereço profissional: Codeplan. Setor de Administração Municipal, SAM, Bloco H, Setores Complementares Brasília, DF. CEP: 70620-080

\section{Marcus Vinícius Lopes Bezerra}

E-mail: bezerra.marcus@gmail.com

Formação: Mestrando em Propriedade Intelectual e Transferência de Tecnologia e Inovação, pela Universidade de Brasília; e pós-graduado em Gestão de Projetos, pela Universidade Católica de Brasília.

Endereço profissional: Sebrae. SGAS 605, conjunto A - Brasília, DF. CEP: 70200-904.

\section{Marina Couto Giordano de Oliveira}

E-mail: marina.giordano79@hotmail.com

Formação: Mestranda em Propriedade Intelectual e Transferência de Tecnologia para Inovação, pelo Programa de Pós-Graduação em Propriedade Intelectual e Transferência de Tecnologia para a Inovação da Universidade de Brasília (PROFNIT/UnB); especialista em Civil e Processo Civil; e bacharela em Direito e Letras-Tradução. Endereço profissional: Embrapa. STN Edifício Sede da Embrapa, Asa Norte - Brasília, DF. CEP: 70770-901.

\section{Sânya Léa Alves Rocha Lopes}

E-mail: sanyalea.a@gmail.com

Formação: Mestranda em Propriedade Intelectual e Transferência de Tecnologia para Inovação, pelo Programa de Pós-Graduação em Propriedade Intelectual e Transferência de Tecnologia para a Inovação da Universidade de Brasília (PROFNIT/UnB); bacharela em Direito, pela Faculdades Integradas da União Educacional do Planalto Central (2011).

Endereço profissional: Ministério da Ciência, Tecnologia, Inovações e Comunicações. EMI Bloco E - Brasília, DF. CEP: 70067-900. 


\section{Adriana Regina Martin}

E-mail: adrianamartin@unb.br

Formação: Pós-Doutora em Inovação Tecnológica, pela UFSCar; doutora e mestra em Ciência e Engenharia dos Materiais, pela UFSCar, com doutorado Sandwich na Universidade de Wisconsin-Madison/USA e Bolsa Fulbright; pós-graduada em Política e Estratégia, pela ADESG; e bacharela e licenciada em Química, pela UFSCar.

Endereço profissional: Ministério da Ciência, Tecnologia, Inovações e Comunicações. Esplanada dos Ministérios, Bloco E - Brasília, DF. CEP: 70067-900.

\section{Paulo Gustavo Barboni Dantas Nascimento}

E-mail: pbarboni@unb.br

Formação: Pós-Doutor em Farmacologia, pela Faculdade de Medicina de Ribeirão Preto (FMRPUSP); doutor em Química, pela FCFRP/USP; mestre em Química, pela Faculdade de Filosofia, Ciências e Letras de Ribeirão Preto da Universidade de São Paulo (FFCLRP/USP); especialista lato sensu em Tecnologias na Aprendizagem, pelo Centro Universitário Senac; e bacharel em Química, pela Universidade de São Paulo (USP).

Endereço profissional: Universidade de Brasília. Campus Ceilândia, QNN14, Área Especial, Ceilândia Sul Brasília, DF. CEP: 72220-140. 